\title{
A Probe into an Applicable Practical Teaching Method with Diverse Collaborations
}

\author{
Xingmin Shi ${ }^{1, a^{*}}$, Junmei Sun ${ }^{1, b}$ and Zhenyu Shan ${ }^{1, c}$ \\ ${ }^{1}$ Hangzhou Normal University, Hangzhou, P.R. China \\ ashixingmin@hznu.edu.cn, bjunmeisun@hznu.edu.cn, cshanzhenyu@zju.edu.cn
}

Keywords: teaching method; diverse collaboration; course assessment; teaching reform

\begin{abstract}
Due to that conventional teaching method mainly focus on the impartment and the memorization of knowledge points, the initiative of student cannot be activated and there is still substantial room for improving the professional abilities, including independent learning ability and problem solving capability, hands-on practical ability, etc. Aiming at improving the teaching results of computer programming courses, a practical mode of classroom instruction with diverse collaboration is proposed in this paper. In this teaching mode, the theoretical teaching and learning is closely integrated with professional practice, opening lab problems and scientific research project. The course assessment emphasizes the project evaluation instead of paper test for proper evaluation of actual practice level of students.
\end{abstract}

\section{Introduction}

Teaching and learning can be seen as an interactive process among the instructor and students. Different teaching patterns can influence the learning outcomes in a distinct way. And the teaching method adopted for a specific course should considerate various factors, including the type of course content, feasible teaching and learning method, as well as the tangible personal situation of students. As a result, it is still an open issue about how to effectively improve the teaching result by utilizing existing method and technologies in higher education. For most courses offered by universities in China, it is currently common to pay more attention to knowledge impartment. Though numerous innovative teaching methods have been proposed and put into practice in the last few years, there is still a very prominent problem that less importance is attached to practical teaching due to the limitation of a prescribed period and the excessive contents of a course.

Problems of Existing Teaching Methods. Firstly, the course assessment concentrates on the recognition and memory ability of knowledge points of a course. The instant feedback from course participants and the development of application capacity attracts relatively little attention. As a result, students can get better examination results. However, the practical capability of the student is not good enough, and the ability to use knowledge need to be improved.

In addition, experimental tasks of a course mainly focus on learning and understanding and the knowledge should be learned in the course. The requirements and the solution of the task or problem have been provided to the students for reference. Opening problems are rarely assigned as the lab project, thus make it impossible to effectively improve the capability of independent thinking and problem solving of students.

Moreover, passive learning [1] is the fundamental mode in the general learning process for students. For most students, their learning goals only focus on accomplishing the learning assignments other than the improvement of their own professional capability. The initiative of the subject of study has not been motivated properly, which result in that it is difficult to achieve a preferable teaching results and the hands-on practice capability is low.

Finally, social and enterprise requirements on talents focus more on practical ability and the capability of business innovation. Accordingly, it is a key issue to explore the effective method which can preferably develop and exploit the subjective initiative of students during the learning process, and effectively improve the professional practical ability of students. 
Currently Available Teaching Methods. In past few years, lots of educators have done a great deal of work to improve the classroom teaching method to improve the teaching results. Various learning and teaching methods have been proposed and put into practice, including case teaching [2], discussion teaching, heuristic teaching, problem-based teaching, research-based teaching, task-based teaching, etc.

Case teaching [3] is based on the principles of case teaching and subjective of learning and focusses on the selection of typical cases related to the knowledge imparted to students. The selected cases can be analyzed, discussed, and then applied into actual applications, thus efficiently bridge the knowledge points and the practice in the teaching. Discussion teaching [4] and heuristic teaching [5] is another two effective teaching mode of improving the ability of students in independent thinking and activating the interest in learning. Problem-based learning method is applicable in engineering education [6], which relies on the problems and discussion of students in learning. Task-based [7] and project-based teaching methods [8] concentrate on developing the practical hands-on capabilities.

Contribution of this Work. The methods mentioned above can achieve better teaching results. However, the subjective initiative cannot be activated in existing course teaching, and the practice still stays at the low level, in which the student can only understand the available cases and problems. The main contribution is a practical mode of classroom instruction with diverse collaboration is proposed. The proposed method in this paper mainly concentrates on the reform of teaching method for computer programming courses. The goal of this teaching scheme is to integrate the advantages of existing efficient teaching methods based on the project, and the open lab projects and the project-centered assessment to improve the teaching results. And meanwhile, the learning process of students can be monitored effectively, and the initiative and the practice level of students can be significantly enhanced.

\section{The Proposed Diverse Collaborative Teaching Method}

The proposed teaching mode focusses on the teaching and learning in the course of the computer programming language and the center of teaching is the subjective, i.e. students. Its goal is to integrate the advantages of existing efficient teaching methods based on the project, and the open lab projects and the project-centered assessment to improve the teaching results. And meanwhile, the learning process of students can be monitored effectively, and the initiative and the practice level of students can be significantly enhanced. As illustrated in Fig. 1, the proposed teaching scheme emphasizes the multiple collaboration of theoretical learning, opening lab projects, scientific research and project-based assessment.

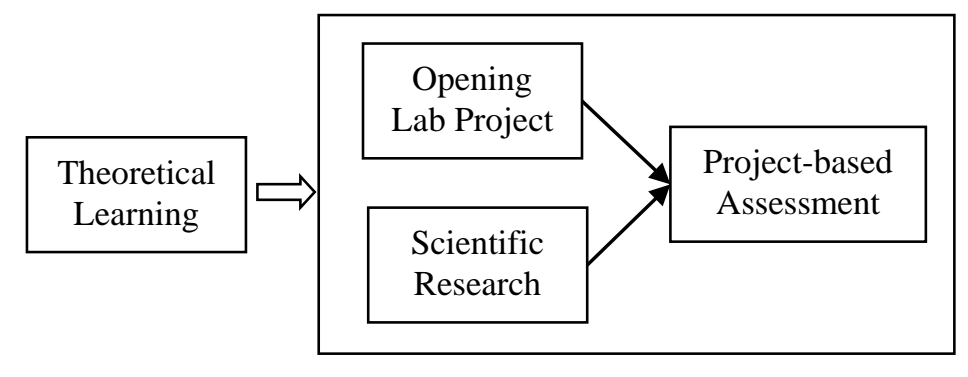

Fig. 1 The diagram of the proposed teaching method with diverse collaboration

Integration of Theoretical Learning and Professional Practice. For the courses of computer programming language, cultivating the ability of students in understanding programming principles and enhancing their practice level are the core of teaching. The collaboration of theoretical learning and the professional practice, i.e. the design and the implementation of software is essential in the proposed mode. This collaboration is achieved by combining the practical case-based teaching method [9] and problem-based teaching mode with theoretical teaching. 
In this collaboration, carefully chosen cases are utilized in the process of theoretical teaching and learning. Selected cases are typical and can cover the import knowledge points of the course content, and there challenging problems remained unsolved are prepared for students. For computer programming courses, the cases generally consists of the basic soft engineering procedures, including requirement acquisition, analysis and design, coding with the programming language, and testing. Basic materials, including the question and the simple analysis of the problem, are provided to students, corresponding implementation tasks will be assigned to students as homework. The combination of theory and practice can significantly activate the interest of learning for students, and the practice level of students can be improved effectively.

Exploitation of Opening Lab Projects. Existing lab assignments provide a relatively fixed experimental process, and the suggested answer has been supplied. Such kind of lab settings is not beneficial to improve the capability of independent thinking and the practical ability in the experimental process. The proposed method suggests that more opening problems should be integrated into the lab assignments.

The selection of opening lab tasks is critical in this teaching scheme. The content of the task should be extensive and prospective for the content learned by students. And the interest in learning is another factor that should be taken into consideration. Moreover, the size of the project is critical, i.e. the lab project can satisfy the requirement of professional training and can be finished within a reasonable period of time. In conclusion, the selected lab tasks should be preferable to improve personal ability in critical thinking and innovation.

Active and Effective Assessment Method. For the course of the computer programming language, the capability of problem solving and hands-on practical abilities is more critical than memorizing knowledge points. The written test is the default mode in the existing course assessment, and emphasizes the importance of memory. Due to the limited period of an exam, the problems in the test paper hardly cover all knowledge points and it is impossible to add more challenging questions related to programming to the examination. As a result, the score from the paper test cannot indicate the actual practice level of students.

In the proposed method, the assessment focus on the project-based evaluation, including system design, implementation using programming language and testing. The goal of such kind of assessment can effectively activate the learning enthusiasm, thus improving the ability of independent learning and problem solving. And the final evaluation can reflect actual learning outcomes of students.

Integration of Research Project and Teaching. Research is seen as the extension of classroom teaching and the carrier of teaching and learning. Around the basic requirements of contents taught in the teaching, a number of students can participate into the project group of the scientific research. This kind of participation can inspire students to find issues and corresponding solutions actively, and their innovation ability can be enhanced significantly. Moreover, learned knowledge can be fully understood and mastered. And finally, personal professional capability can be enhanced greatly.

In addition, the advantages of the participation in scientific projects are reflected following aspects. Firstly, it is helpful for students to fully understand relevant knowledge points, and master the basic principles in software design and programming. Moreover, the team-work spirit and communication skills can be developed during the working in the research group.

The key element of this process lies in the selection of scientific project that can be utilized in the teaching. Projects with moderately difficulty are preferable to activate enthusiasm of students, and put the research work forward steadily. And meanwhile, the specialized capability of students can be improved effectively. If the selected project is too complex, it will be fearful for students.

Application of the Proposed Method. The proposed method has been applied in practical teaching. In the lecture of Java programming language, we provide fifteen cases and eight open lab tasks without any indication of standard answer. A project with appropriate level and size is assigned as the work to be finally assessed in the end of the course. Some talented students join the scientific research group and achieves a better result. 
Through the application of the proposed teaching method, the outcome of the course is improved significantly. Firstly, students can understand and freely use the grammar of coding in Java in coding. In addition, with the help of case study, students understand the knowledge points and its usage in programming. For students attending the course, most of them have developed the capability of independent thinking and can solve the issues in software design and programming. It proves in practice that the proposed method is feasible and effective in improving professional capabilities in computer programming.

\section{Summary}

For overcoming the weakness and the disadvantages of conventional teaching methods and improving the teaching results of computer programming courses, an applicable teaching method with diverse collaboration is proposed in this paper. We proposed a diverse collaboration solution, which incorporates professional practice, opening lab problems, scientific research project and the innovative project-based assessment in classroom teaching. The practice of the proposed method shows that the mode of diverse collaboration is effective in developing the capability of critical thinking, the ability of independent problem solving and creative ability.

\section{Acknowledgement}

This work is supported in part by the fund of the Teaching Reform Projects of Hangzhou Normal University, 2014.

\section{References}

[1] Lianying Zhou, Hebiao Yang, Ling Jiang, On autonomous learning and classroom teaching design at universities, in: International Conference on Consumer Electronics, Communications and Networks, 2012, pp. 3344-3348.

[2] Juan Zhou, Cheng Chen, Research on the Case Teaching of Assets Evaluation Course, in: IEEE International Symposium on Knowledge Acquisition and Modeling Workshop, 2008, pp. 852-855.

[3] Rozilawati Razali, Mahsa Chitsaz, Cases development for teaching software engineering, in: International Conference on Education Technology and Computer, 2010, pp. 121-125.

[4] Laura K. Simmons, Discussion-based online teaching to enhance student learning: theory, practice and assessment - Tisha Bender, Teaching Theology and Religion. 9(2006) 194-195.

[5] Li Chengbiao, Zhang Qin, A research on application of heuristic teaching methods in the teaching of management, in: International Workshop on Education Technology and Computer Science, 2009, pp. 762-766.

[6] David Santos-Martin, Jaime Alonso-Martinez, Joaquin Eloy-Garcia Carrasco, Santiago Arnaltes, Problem-based learning in wind energy using virtual and real setups, IEEE Transactions on Education. 55(2012) 126-134.

[7] David R. Carless, Factors in the implementation of task-based teaching in primary schools, System. 31(2003) 485-500.

[8] Zhao Weidong, Wu Haifeng, Wang Anhua, Research-based teaching in artificial intelligence course, in: International Conference on Computer Science \& Education, 2009, pp. 1756-1759.

[9] Yasemin Demiraslan Cevik, Thomas Andre, Examining Preservice Teachers' Classroom Management Decisions in Three Case-Based Teaching Approaches, International Journal of Education in Mathematics, Science and Technology. 1 (2013) 25-42. 